\title{
Association Analysis of Methylenetetrahydrofolate Reductase Common Gene Polymorphisms with Breast Cancer Risk in an Iranian Population: A Case-Control Study and a Stratified Analysis
}

\author{
Mohammad Karimian ${ }^{1}$, Nasrin Rezazadeh ${ }^{2 *}$, Tahereh Khamehchian ${ }^{2 *}$
}

\begin{abstract}
Genetic polymorphisms in the methylenetetrahydrofolate reductase (MTHFR) gene may alter the risk of breast cancer. This study aimed to investigate the association of MTHFR C677T and A1298C genetic polymorphisms with breast cancer risk in case-control studies which was followed by stratified analysis. In the case-control study, 300 subjects including 150 women with breast cancer and 150 healthy women were enrolled. After blood sample collection, the C677T and A1298C polymorphisms genotyping were done by the PCR-RFLP method. Our data revealed a significant association between MTHFR C677T and A1298C polymorphisms and breast cancer risk. But, as a preliminary study, stratified analysis revealed no significant association between C677T and A1298C polymorphisms and tumor size and also lymph node metastasis in breast cancer. According to the mentioned findings, the C677T and A1298C polymorphisms in the MTHFR gene could be molecular risk factors for breast cancer in our studied population. However, further studies with larger sample sizes are required to obtain a more accurate conclusion in stratified analysis.
\end{abstract}

Keywords: Breast cancer- MTHFR- genetic polymorphism- risk factor

Asian Pac J Cancer Prev, 21 (9), 2709-2714

\section{Introduction}

Breast cancer is one of the most common causes of death in women worldwide (Bray et al., 2018). This malignancy is also considered as the most prevalent cancer in women worldwide (Fares et al., 2019). Breast cancer is a complex and multifactorial disease that could be affected by various genetic and environmental factors. For instance, age over 40 years, history of some proliferative breast diseases, history of breast cancer in the first-degree family, early menstruation, late menopause, nulliparity, and higher socioeconomic status (Kamińska et al., 2015). Genetic factors also play an important role in tumor formation and progression. For example, aneusomy of chromosome 17, deletion of loci at 16q, 11q, 6q, and $3 p$ and polymorphisms in genes involved in the key cellular pathways can be the main risk factors for breast cancer (Newsham, 1998). One of the important cellular pathways is the folate metabolism cycle which includes many genes such as methylenetetrahydrofolate reductase (MTHFR), methionine synthase (MTR), and methionine synthase reductase (MTRR). The role of the MTHFR enzyme is to convert 5,10-methylenetetrahydrofolate (5,10-MTHF) to 5-methyltetrahydrofolate (5-MTHF), which is a common substrate for methylation of homocysteine to methionine. The methyl group of methionine is used to form S-adenosyl methionine which is a methyl donor for DNA and protein methylation (Shrubsole et al., 2004). This gene consists of numerous single nucleotide polymorphisms (SNPs). The C677T (rs1801133) and A1298C (rs1801131) genetic variations are the most common polymorphisms of the MTHFR gene which may contribute to breast cancer risk. The $\mathrm{C} 677 \mathrm{~T}$ polymorphism results in alanine to valine replacement at the codon 222 . While the A1298C polymorphism replaces glutamate to alanine at codon 429 (Hesari et al., 2019).

There are some studies that investigated the correlation of two common polymorphisms (C677T and A1298C) in MTHFR gene with the breast cancer risk. Kaya et al in 2016 reported no significant association between C677T polymorphism and breast cancer risk (Kaya et al., 2016). Also, Papandreou et al. in 2012 reported no significant association between $\mathrm{A} 1298 \mathrm{C}$ and breast cancer risk (Papandreou et al., 2012). However, Ergul et al., (2003) reported a significant association between two mentioned SNPs and breast cancer risk (Ergul et al., 2003). Given the

${ }^{1}$ Department of Molecular and Cell Biology, Faculty of Basic Sciences, University of Mazandaran, Babolsar, Iran. 2Department of Pathology, School of Medicine, Kashan University of Medical Sciences, Kashan, Iran. *For Correspondence: rezazadeh.nasrin2@gmail.com, taherehkhamehchian@gmail.com 
above contradictory results, the purpose of this study is to determine the association of C677T and A1298C SNPs of the MTHFR gene with breast cancer risk in a case-control study which is followed by stratified analysis.

\section{Materials and Methods}

\section{Subjects}

This study consisted of 150 breast cancer patients and 150 cancer-free and age-matched women. Case individuals were the patients referring to Hospitals in Isfahan province and their breast cancer was confirmed by pathological tests. They completed a questionnaire containing information about their BMI, history of drug, age, and family history of breast cancer. Patients with diseases such as diabetes, other cancers, CHD, and etc. were excluded from the study. The control group was composed of healthy women without a family history of cancer and other disorders who were referring to the same hospitals for routine examinations. Both cases and controls were belonging to a local area with the same ethnicity. All participants signed an informed consent form and this project was approved by the ethics committee of the Kashan University of Medical Sciences (IR. KAUMS.MEDNT.REC.1397.39). Approximately $2 \mathrm{ml}$ of blood was taken from each woman and transferred to an EDTA-coagulated tube and stored at $-20^{\circ} \mathrm{C}$ until DNA extraction.

\section{DNA extraction and SNPs genotyping}

DNA was extracted from peripheral blood samples by a commercial DNA extraction kit (Bioneer, Daejeon, Korea). polymerase chain reaction-restriction fragment length polymorphism (PCR-RFLP) method was used to C677T and A1298C SNPs genotyping. For this purpose, at first, forward and reverse oligonucleotide primers were deduced from our previous study (Karimian and Colagar, 2016) and were ordered from Bioneer Company to amplify fragments containing two mentioned SNPs. Approximately 5 microliters of twice-distilled water were added to $0.2 \mathrm{ml}$ micro-tubes to reach a final volume of $20 \mu 1$. Then, $10 \mu 1$ of $2 \mathrm{X}$ premix PCR mixture, $0.3 \mu \mathrm{M}$ of each pair of primers, and 60ng of DNA template were added to the micro-tubes. After a short vortex and then spin the samples, PCR was performed in a Peqlab thermal cycler (PEQLAB Biotechnologie GmbH, Germany). All PCR reagents were ordered from Cinnagen company (Cinnagen, Tehran, Iran). The thermal cycling conditions for PCR were as follows: initial denaturation at $94^{\circ} \mathrm{C}$ for $4 \mathrm{~min}$, then 35 cycles of denaturation at $94^{\circ} \mathrm{C}$ for $30 \mathrm{~min}$, annealing at $63^{\circ} \mathrm{C}$ for $30 \mathrm{~min}$ for $\mathrm{C} 677 \mathrm{~T}$ polymorphism and $67^{\circ} \mathrm{C}$ for $\mathrm{A} 1298 \mathrm{C}$, and elongation at $72^{\circ} \mathrm{C}$ for 30 min, with a final extension at $72^{\circ} \mathrm{C}$ for $5 \mathrm{~min}$. The PCR products were digested by the HinfI enzyme for the C677T variant and MboII enzyme for A1298C SNP according to manufacturer's instruction (Fermentas, Waltham, Massachusetts, United States).

PCR products were electrophoresed on 1\% agarose gel and the fragments containing $\mathrm{C} 677 \mathrm{~T}$ and $\mathrm{A} 1298 \mathrm{C}$ variations produced the bands with a length of 233-bp and 143-bp, respectively. The genotypes of $6677 \mathrm{~T}$ polymorphism was detected by $2 \%$ agarose gel electrophoresis. The fragment with TT genotype was digested into two 176-bp and 57-bp fragments, whereas in CT genotype was digested into 233-bp, 176-bp, and 57-bp fragments. In CC genotype, only one band containing the 233-bp fragment was observed because there was no restriction site for HinfI (Figure 1). Regarding A1298C polymorphism, the 143-bp digested fragment on $8 \%$ polyacrylamide gel demonstrated two bands of 108-bp and 37-bp for CC genotype, three bands of 37-bp and 79-bp, and 29-bp for AA genotype, and four bands of 108-bp, 79-bp, 37-bp, and 29-bp for AC heterozygote genotype (Figure 1). For PCR-RFLP verification, three samples of PCR products with $\mathrm{CC}, \mathrm{CT}$, and TT genotypes for C677T polymorphism and three samples with CC, AC, and AA genotypes for A1298C polymorphism were respectively sequenced using forward and reverse primers by Bioneer Company.

\section{Statistical analysis}

Statistical tests were performed using SPSS 22 software (SPSS Inc., IBM Corp Armonk, NY, USA). The Chi-square test was used to compare alleles and genotypes frequencies in case and control groups. This test was also used to evaluate Hardy-Weinberg equilibrium in both the cases and healthy control groups. A binary logistic regression was used to obtain odds ratio (OR) and $95 \%$ confidence interval (CI) for investigation of the association between the two polymorphisms and the risk of breast cancer in overall and stratified analyses. A two-tailed p-value of less than 0.05 was considered statistically significant.

\section{Results}

Association of C677T and A1298C SNPs with breast cancer

The results of genetic association analysis for $\mathrm{C} 677 \mathrm{~T}$ and A1298C polymorphisms are summarized in Table 1. Distribution of genotypes in case and control groups for both mentioned SNPs was consistent with Hardy-Weinberg equilibrium criteria. Concerning C677T polymorphism, the $\mathrm{C}$ allele was more prevalent than another allele. The frequency of allele $\mathrm{T}$ in the patient group was significantly higher than the control group and statistical analysis showed that there was a significant correlation between $\mathrm{T}$ allele and increased risk of breast cancer $(\mathrm{OR}=2.31$, $95 \% \mathrm{CI}=1.58-3.38, \mathrm{p}<0.0001)$. The frequency of $\mathrm{CT}$ genotype in control and patient groups was $25.33 \%$ and $47.33 \%$, respectively while these ratios for the TT genotype were $5.40 \%$ and $10.00 \%$, respectively. Statistical analysis showed a significant association between $\mathrm{CT}$ $(\mathrm{OR}=3.04,95 \% \mathrm{CI}=1.84-5.02, \mathrm{p}<0.0001)$ and $\mathrm{TT}$ $(\mathrm{OR}=3.05,95 \% \mathrm{CI}=1.22-7.59, \mathrm{p}=0.017)$ genotypes and increased risk of breast cancer. Besides, carriers of T allele were at high risk for breast cancer susceptibility $(\mathrm{OR}=$ 2.31, 95\% CI $=1.58-3.38, \mathrm{p}<0.0001)$. Regarding A1298C polymorphism, our data showed that the $\mathrm{C}$ allele was more prevalent than A allele in the case and control groups. The frequency of genotype $\mathrm{AC}$ in control and case group was $38.67 \%$ and $39.33 \%$, respectively while these ratios for CC genotype were $8.66 \%$ and $16.67 \%$, respectively. Statistical 
Table 1. Association of MTHFR-C677T and MTHFR-A1298C polymorphisms with breast cancer risk

\begin{tabular}{|c|c|c|c|c|c|}
\hline Genotype/Allele & Case $(n=150)$ & Control $(\mathrm{n}=150)$ & $\chi 2$ value & OR $(95 \% \mathrm{CI})$ & $P$-value \\
\hline \multicolumn{6}{|c|}{ A) $M T H F R-C 677 \mathrm{~T}$} \\
\hline $\mathrm{CC}$ & $64(42.67 \%)$ & $104(69.33 \%)$ & - & - & - \\
\hline $\mathrm{CT}$ & $71(47.33 \%)$ & $38(25.33 \%)$ & 19.35 & $3.04(1.84-5.02)$ & $<0.0001 *$ \\
\hline TT & $15(10.00 \%)$ & $8(5.40 \%)$ & 6.14 & $3.05(1.22-7.59)$ & $0.017^{*}$ \\
\hline $\mathrm{CT}+\mathrm{TT}$ & $86(57.33 \%)$ & $46(30.66 \%)$ & 21.65 & $3.04(1.89-4.88)$ & $<0.0001^{*}$ \\
\hline $\mathrm{C}$ & $199(66.33 \%)$ & $246(82.00 \%)$ & - & - & - \\
\hline $\mathrm{T}$ & $101(33.67 \%)$ & $54(18.00 \%)$ & 19.22 & $2.31(1.58-3.38)$ & $<0.0001 *$ \\
\hline \multicolumn{6}{|c|}{ B) $M T H F R-A 1298 \mathrm{C}$} \\
\hline AA & $66(44.00 \%)$ & $79(52.67 \%)$ & - & - & - \\
\hline $\mathrm{AC}$ & $59(39.33 \%)$ & $58(38.67 \%)$ & 0.63 & $1.22(0.75-1.98)$ & 0.429 \\
\hline $\mathrm{CC}$ & $25(16.67 \%)$ & $13(08.66 \%)$ & 4.95 & $2.30(1.09-4.85)$ & $0.028 *$ \\
\hline $\mathrm{AC}+\mathrm{CC}$ & $84(56.00 \%)$ & $71(47.34 \%)$ & 2.26 & $1.42(0.90-2.23)$ & 0.134 \\
\hline A & $191(63.67 \%)$ & $216(72.00 \%)$ & - & - & - \\
\hline $\mathrm{C}$ & $109(36.33 \%)$ & $84(28.00 \%)$ & 4.77 & $1.47(1.04-2.07)$ & $0.029 *$ \\
\hline
\end{tabular}

OR, odds ratio; CI, confidence interval. *Significant differences between cases and controls.

analysis showed that the CC genotype has a significant correlation with increased risk of breast cancer $(\mathrm{OR}=$ $2.30,95 \% \mathrm{CI}=1.09-4.85, \mathrm{p}=0.028)$. Also, the frequency of the $\mathrm{C}$ allele in the patient group was significantly higher than the control group and subsequent analysis showed a significant association between $\mathrm{C}$ allele and increased risk of breast cancer $(\mathrm{OR}=1.47,95 \% \mathrm{CI}=1.04-2.07, \mathrm{p}=0.029)$.

\section{Stratified analysis}

The genotypes distribution for C677T and A1298C polymorphisms were evaluated for size of tumor and metastasis of lymph node in breast cancer subjects (Table 2). Concerning C677T polymorphism, we found no true associations between this variation and tumor size of breast malignancy (CT vs. $\mathrm{CC}: \mathrm{OR}=1.31,95 \% \mathrm{CI}=0.63$ $2.72, p=0.477$; TT vs. $\mathrm{CC}: \mathrm{OR}=1.70,95 \% \mathrm{CI}=0.53-5.48$, $\mathrm{p}=0.371 ; \mathrm{CT}+\mathrm{TT}$ vs. $\mathrm{CC}: \mathrm{OR}=1.37,95 \% \mathrm{CI}=0.68-2.76$, $\mathrm{p}=0.381)$. Such results were observed for lymph node metastasis (CT vs. $\mathrm{CC}: \mathrm{OR}=1.12,95 \% \mathrm{CI}=0.57-2.23$, $\mathrm{p}=0.733$; TT vs. $\mathrm{CC}: \mathrm{OR}=1.56,95 \% \mathrm{CI}=0.48-5.07, \mathrm{p}=$

Table 2. The Association Analysis between MTHFR-C677T and MTHFR-A1298C Variation with Two Cclinical Characteristics of Breast Cancer

\begin{tabular}{|c|c|c|c|c|}
\hline \multicolumn{5}{|l|}{ A) $M T H F R-C 677 \mathrm{~T}$} \\
\hline \multirow[t]{2}{*}{ Characteristics } & \multicolumn{4}{|c|}{ Genotype distributions } \\
\hline & $\mathrm{CC}$ & $\mathrm{CT}$ & TT & $\mathrm{CT}+\mathrm{TT}$ \\
\hline \multicolumn{5}{|l|}{ Tumor size $(\mathrm{cm})$} \\
\hline$\geq 2 /<2$ & $18 / 46$ & $24 / 47$ & $6 / 9$ & $30 / 56$ \\
\hline OR $(95 \% \mathrm{CI})$ & 1.0 (reference) & $1.31(0.63-2.72)$ & $1.70(0.53-5.48)$ & $1.37(0.68-2.76)$ \\
\hline p-value & - & 0.477 & 0.371 & 0.381 \\
\hline \multicolumn{5}{|c|}{ Lymph node metastasis } \\
\hline Yes/No & $36 / 28$ & $42 / 29$ & $5-$-Oct & $52 / 34$ \\
\hline OR $(95 \% \mathrm{CI})$ & 1.0 (reference) & $1.12(0.57-2.23)$ & $1.56(0.48-5.07)$ & $1.19(0.62-2.29)$ \\
\hline $\mathrm{p}$-value & - & 0.733 & 0.464 & 0.604 \\
\hline \multicolumn{5}{|l|}{ B) $M T H F R-A 1298 \mathrm{C}$} \\
\hline \multirow[t]{2}{*}{ Characteristics } & \multicolumn{4}{|c|}{ Genotype distributions } \\
\hline & AA & $\mathrm{AC}$ & $\mathrm{CC}$ & $\mathrm{AC}+\mathrm{CC}$ \\
\hline \multicolumn{5}{|l|}{ Tumor size $(\mathrm{cm})$} \\
\hline$\geq 2 /<2$ & $16 / 50$ & $21 / 38$ & 14-Nov & $32 / 52$ \\
\hline OR $(95 \% \mathrm{CI})$ & 1.0 (reference) & $1.73(0.80-3.75)$ & $2.46(0.93-6.48)$ & $1.92(0.94-3.93)$ \\
\hline p-value & - & 0.167 & 0.07 & 0.073 \\
\hline \multicolumn{5}{|c|}{ Lymph node metastasis } \\
\hline Yes/No & $40 / 26$ & $36 / 23$ & 13-Dec & $48 / 36$ \\
\hline OR $(95 \% \mathrm{CI})$ & 1.0 (reference) & $1.02(0.50-2.09)$ & $0.60(0.24-1.52)$ & $0.87(0.45-1.67)$ \\
\hline p-value & - & 0.963 & 0.28 & 0.67 \\
\hline
\end{tabular}



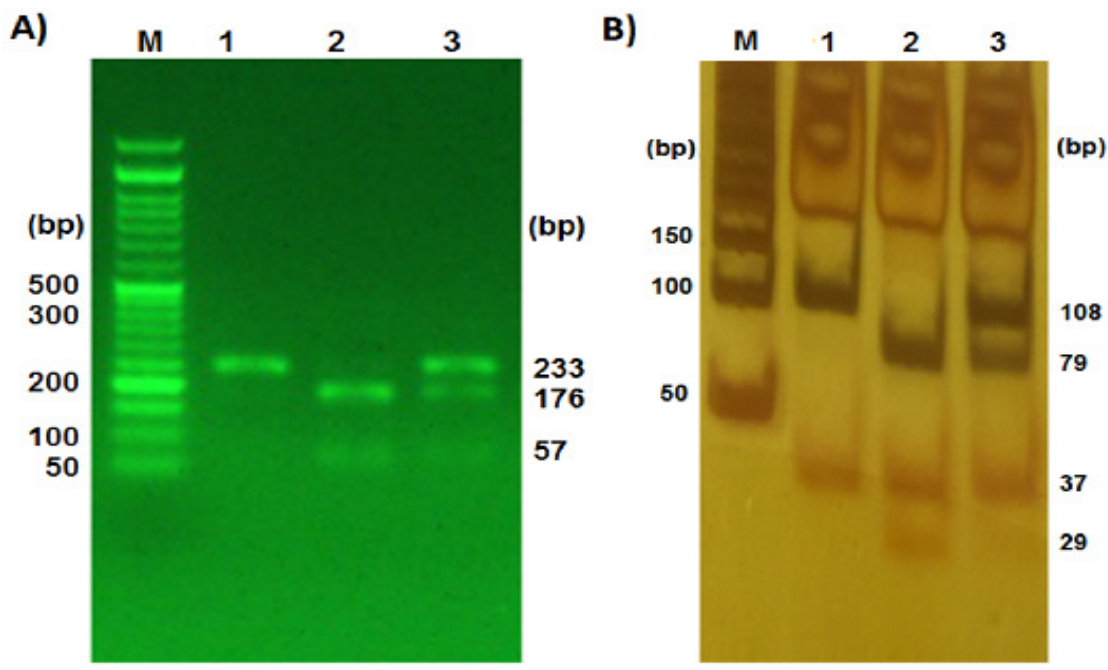

Figure 1. Polymorphism Analysis of MTHFR-C677T and MTHFR-A1298C. A) The PCR products containing C677T variation which digested with Hinf I restriction enzyme (lane M, DNA marker; Lane 1, CC genotype; Lane 2, TT genotype; Lane 3, CT genotype); B) The PCR products containing A1298C variation which digested with MboII restriction enzyme (lane M, DNA marker; Lane 1, CC genotype; Lane 2, AA genotype; Lane 3, AC genotype).

0.464; CT+TT vs. CC: $\mathrm{OR}=1.19,95 \% \mathrm{CI}=0.62-2.29$, $\mathrm{p}=0.604)$. Also, we did not observe any significant correlation between A1298C variation and tumor size and also lymph node metastasis of breast malignancy (Table 2). Our data showed that this variation could not be associated with the tumor size in three genetic model analysis. The same results were observed for lymph node metastasis in three genetic models analysis (AC vs. AA: $\mathrm{OR}=1.02,95 \% \mathrm{CI}=0.50-2.09, \mathrm{p}=0.963 ; \mathrm{CC}$ vs. $\mathrm{AA}: \mathrm{OR}=$ $0.60,95 \% \mathrm{CI}=0.24-1.52, \mathrm{p}=0.280 ; \mathrm{AC}+\mathrm{CC}$ vs. $\mathrm{AA}: \mathrm{OR}=$ $0.87,95 \% \mathrm{CI}=0.45-1.67, \mathrm{p}=0.670)$.

\section{Discussion}

In the present study, we evaluated the association of two common variations in the MTHFR gene with the risk of breast cancer in a case-control study which was followed by stratified analysis. Our case-control study revealed a significant association between A1298C and C677T genetic variation and increased risk of breast cancer in our studied population. But, there are some similar studies with inconsistent results. This phenomenon, may be due to different behavior of polymorphism in various races. However, environmental and nutritional factors are also involved in the effect of this polymorphism.

Folate, a form of vitamin B9, is found chiefly in plant diets. The human cell requires folate as a cofactor for numerous reactions, such as DNA synthesis, DNA methylation, and DNA repair (Ericson et al., 2009). Then diets deficient in fruits and vegetables are generally low in folate, antioxidants, and a lot of other micronutrients which leads to significant amounts of DNA damage and higher cancer rates (Blount et al., 1997). Low consumption of folate and related B vitamins plays as one of the few risk factors associated with breast cancer (Chen et al., 2005). Some studies revealed that folate intake to be inversely associated with the risk of breast cancer (Campbell et al., 2002; Ericson et al., 2009). Wang et al., (2014) and Weiwei et al., (2014) found a significant association of MTHFR-C677T transition and folate intake with risk of breast cancer, and they reported a significant interaction between folate intake and MTHFR-C677T transition (Wang et al., 2014; Weiwei et al., 2014). Also, Ericson et al., (2009) suggested a significant association of high concentration of folate with the risk of postmenopausal breast cancer risk in carriers of the MTHFR-677T allele. Generally, the role of folate to the prevention of tumor development before preneoplastic lesions have been proven, but it conversely increases tumorigenesis once lesions. However, increase the folate intake in women with already-sufficient levels of folate may be harmful (Ma et al., 2009). Shrubsole et al., 2004 evaluated C677T and A1298C variations and their impacts on the folate intake and association of breast cancer susceptibility. They reported an inverse correlation of breast cancer risk with the intake of folate for all genotypes, especially among subjects with the 677TT genotype. They suggested that MTHFR-C677T variation might modify the correlation of dietary folate intake with breast cancer risk. But, there was no modifying effect of A1298C genotypes on the correlation of folate intake with the risk of breast cancer (Shrubsole et al., 2004).

Consequently, the MTHFR enzyme has a balancing role in the pool of methyl groups for DNA methylation, protein methylation, and DNA synthesis (Ericson et al., 2009). Thus, MTHFR activity may affect both gene expression (by DNA methylation), and genome integrity (by DNA synthesis and repair) (Le Marchand et al., 2004). The potential impact of MTHFR enzyme activity on DNA methylation, synthesis, and repair make it a possible candidate in cancer-predisposing (Campbell et al., 2002). The SNP's effects on the molecular aspects of a gene were dependent on its gene location (Karimian et al.,(2020); Mobasseri et al., 2019). Evaluation of these effects by in vitro and in vivo methods is very time and cost consuming (Zamani-Badi et al., 2018; Bafrani et al., 2019). Assessment of the mentioned impacts and other molecular assessments by in silico tools may be too beneficial (Noureddini et al., 2018; Tameh et al., 2018). A study with bioinformatics analysis revealed that both 
C677T and A1298C genetic variations made significant changes in the secondary structure of MTHFR-mRNA. Moreover, a structural examination of the A1298C polymorphism showed a significant impact on the function of MTHFR (Salimi et al., 2017).

In conclusion, based on our findings, the MTHFRA1298C and MTHFR-C677T variations could be genetic risk factors in our studied population. But, these polymorphisms could not be considered as genetic risk factors for tumor size and lymph node metastasis in our studied population. However, there are some limitations in our study, for example, a small sample size in the case-control study especially in the stratified analysis is the main limitation. Also, lack of evaluation of folate and homocysteine level is another limitation of our project. On the other hand, lack of attention to gene-environment and environment-environment interactions are other limitations of our study. However, further studies with a larger sample size regarding the aforementioned interactions could be helpful to obtain more accurate data.

\section{Acknowledgements}

We thank all subjects participating in this project.

\section{Funding}

This work was supported by a grant from the Kashan University of Medical Sciences (Grant No. 97064).

\section{Ethical statement}

All participants signed an informed consent form and this project was approved by the ethics committee of the Kashan University of Medical Sciences (IR.KAUMS. MEDNT.REC.1397.39).

\section{Author contributions}

MK and TK: designing the study, and writing the manuscript. TK and NR: pathological diagnosis. MK and NR: performing the experimental tests and collecting the data.

\section{Competing interests}

The authors declare that they have no conflict of interest.

\section{References}

Bafrani HH, Ahmadi M, Jahantigh D, et al (2019). Association analysis of the common varieties of IL17A and IL17F genes with the risk of knee osteoarthritis. J Cell Biochem, 120, 18020-30.

Blount BC, Mack MM, Wehr CM, et al (1997). Folate deficiency causes uracil misincorporation into human DNA and chromosome breakage: implications for cancer and neuronal damage. Proc Natl Acad Sci U S A, 94, 3290-5.

Bray F, Ferlay J, Soerjomataram I, et al (2018). Global cancer statistics 2018: GLOBOCAN estimates of incidence and mortality worldwide for 36 cancers in 185 countries. $C A$ Cancer J Clin, 68, 394-424.

Campbell IG, Baxter SW, Eccles DM, et al (2002). Methylenetetrahydrofolate reductase polymorphism and susceptibility to breast cancer. Breast Cancer Res, 4, R14.
Chen J, Gammon MD, Chan W, et al (2005). One-carbon metabolism, MTHFR polymorphisms, and risk of breast cancer. Cancer Res, 65, 1606-14.

Ergul E, Sazci A, Utkan Z, et al (2003). Polymorphisms in the MTHFR gene are associated with breast cancer. Tumor Biol, 24, 286-90.

Ericson UC, Ivarsson MI, Sonestedt E, et al (2009). Increased breast cancer risk at high plasma folate concentrations among women with the MTHFR 677T allele. Am J Clin Nutr, 90, 1380-9.

Fares MY, Salhab HA, Khachfe HH, et al (2019). Breast cancer epidemiology among Lebanese women: an 11-year analysis. Medicina, 55, 463.

Hesari A, Maleksabet A, Tirkani AN, et al (2019). Evaluation of the two polymorphisms rs 1801133 in MTHFR and rs10811661 in CDKN2A/B in breast cancer. JCell Biochem, 120, 2090-7.

Kamińska M, Ciszewski T, Łopacka-Szatan K, et al (2015). Breast cancer risk factors. Prz Menopauzalny, 14, 196.

Karimian M, Colagar AH (2016). Association of C677T transition of the human methylenetetrahydrofolate reductase (MTHFR) gene with male infertility. Reprod Fertil Dev, 28, 785-94.

Karimian M, Momeni A, Farmohammadi A, et al (2020). Common gene polymorphism in ATP-binding cassette transporter A1 and coronary artery disease: A genetic association study and a structural analysis. J Cell Biochem, 121, 3345-57.

Kaya EF, Karakus N, Ulusoy AN, et al (2016). Association of the MTHFR gene C677T polymorphism with breast cancer in a Turkish population. Oncol Res Treat, 39, 534-8.

Le Marchand L, Haiman CA, Wilkens LR, et al (2004). MTHFR polymorphisms, diet, HRT, and breast cancer risk: the multiethnic cohort study. Cancer Epidemiol Biomarkers Prev, 13, 2071-7.

Ma E, Iwasaki M, Kobayashi M, et al (2009). Dietary intake of folate, vitamin B2, vitamin B6, vitamin B12, genetic polymorphism of related enzymes, and risk of breast cancer: a case-control study in Japan. Nutr Cancer, 61, 447-56.

Mobasseri N, Nikzad H, Karimian M (2019). Protective effect of oestrogen receptor $\alpha$-PvuII transition against idiopathic male infertility: a case-control study and meta-analysis. Reprod Biomed Online, 38, 588-98.

Newsham IF (1998). The long and short of chromosome 11 in breast cancer. Am J Pathol, 153, 5.

Noureddini M, Mobasseri N, Karimian M, et al (2018). Arg399Gln substitution in XRCC1 as a prognostic and predictive biomarker for prostate cancer: Evidence from 8662 subjects and a structural analysis. J Gene Med, 20, e3053.

Papandreou CN, Doxani C, Zdoukopoulos N, et al (2012). Evidence of association between methylenetetrahydrofolate reductase gene and susceptibility to breast cancer: a candidate-gene association study in a South-eastern European population. DNA Cell Biol, 31, 193-8.

Salimi S, Keshavarzi F, Mohammadpour-Gharehbagh A, et al (2017). Polymorphisms of the folate metabolizing enzymes: Association with SLE susceptibility and in silico analysis. Gene, 637, 161-72.

Shrubsole MJ, Gao Y-T, Cai Q, et al (2004). MTHFR polymorphisms, dietary folate intake, and breast cancer risk: results from the Shanghai Breast Cancer Study. Cancer Epidemiol Biomarkers Prev, 13, 190-6.

Tameh AA, Karimian M, Zare-Dehghanani Z, et al (2018). Role of steroid therapy after ischemic stroke by n-methyld-aspartate receptor gene regulation. J Stroke Cerebrovasc Dis, 27, 3066-75. 
Wang Z, Cui W, Yang L, et al (2014). Association of dietary intake of folate and MTHFR genotype with breast cancer risk. Genet Mol Res, 13, 5446-545.

Weiwei Z, Liping C, Dequan L (2014). Association between dietary intake of folate, vitamin B6, B12 \& MTHFR, MTR Genotype and breast cancer risk. PakJ Med Sci, 30, 106.

Zamani-Badi T, Nikzad H, Karimian M (2018). IL-1RA VNTR and IL-1 $\alpha 4845 \mathrm{G}>\mathrm{T}$ polymorphisms and risk of idiopathic male infertility in Iranian men: A case-control study and an in silico analysis. Andrologia, 50, e13081.

\section{c) (i) (8)}

This work is licensed under a Creative Commons AttributionNon Commercial 4.0 International License. 